\title{
Effect of Glycine Betaine on Morphological and Physiological Attributes of Tomato (Lycopersicon esculentum L.) Cultivars under Saline Conditions
}

\author{
Muhammad Shahzad ${ }^{1} \mathrm{a}^{*}$, Karim Yar Abbasi ${ }^{2}$, Ali Shahzad ${ }^{1}$, Farrah Zaidi ${ }^{1}$ \\ ${ }^{1}$ Department of Botany, University of Agriculture, Faisalabad, Pakistan \\ ${ }^{2}$ Institute of Horticultural Sciences, University of Agriculture, Faisalabad, Pakistan \\ a*Shahzad2862@yahoo.com
}

\begin{abstract}
Keywords: Hoagland solution, morphological and physiological aspects, glycine betaine.
\end{abstract}
\begin{abstract}
Tomato (Lycopersicon esculentum L.) is a long duration crop belongs to a family Solanaceae. In case of vegetables, tomato is a second major crop, cultivated wide range throughout the world. Although, tomato is moderate sensitive to salinity yet for salinity tolerance more attention is required. More than $30 \%$ cultivated land all over the world severely affected by the salinity. In this scenario, experiment was designed to investigate various morphological and physiological aspects of tomato under various salinity levels; different levels of exogenous glycine betaine applications. Study was conducted to reveal the salt tolerance in tomato genotypes. Experiment was performed under controlled condition in the growth chamber of the IHS, UAF. Different concentrations of sodium chloride salt $\left(0,1.5\right.$ and $\left.3 \mathrm{dS} \mathrm{m}^{-1}\right)$ was used for salinity levels. Medium size plastic pots were used for sowing of tomato and sand was used as growing medium. Hoagland solution was applied for nourishment of tomato seedlings. Salinity was applied on 3-4 leaf stage. Then examined the effect of glycine betaine $(0,5,10$ and $15 \mathrm{mM})$ for salt tolerance on tomato cultivars. Data of various attributes was collected and analyzed statistically by appropriate statistical package. Results revealed that tomato growth was negatively affected by the salinity. Morphological attributes and physiological attributes reduced in response to salinity except electrolyte leakage which amplified in salt stress. Exogenous application of glycine betaine promotes the tolerance against the salinity in the tomato genotypes and enhance growth.
\end{abstract}

\section{Introduction}

Tomato from family solanaceae is one of the chief vegetal crop, cultivated worldwide. Globally, tomato was cultivated on 4.8 million hectares with production of a 178 million tonnes in 2016 [1]. Tomato production during 2013-14 in Pakistan was 599 thousand tonnes [2]. This crop is cultivated in broader range of climatic conditions, but most favorable areas for cultivation are warm and relatively dry [3] and in these arid and semiarid regions high soil salinity and water stress are the two common environmental stresses [4]. Environmental stress that inhibit the growth of crops salinity one of them [5]. Changes occurred in plant cell structure due to saline conditions [6,7] and unswervingly affected the biochemical attributes, physiological and morphological attributes of plants [8] Saline conditions affected the growth development, protein production and respiration $[9,10]$.

Cope the salinity affect, plants adapted various changes in morphological and physiological attributes [11,12] Synthesis and gathering of compatible solutes (Osmolytes/metabolites) is common strategy in plants to protect them from environmental stresses [13]. The gathering of osmolytes help to overcome the oxidative damage triggered by free radicals produced as result of high salt stress and also sustain damage of subcellular structure.

Glycine betaine $(\mathrm{GB})$ is one of the osmolyte which is quaternary ammonium compound and in some plants its accumulation is communal retort to lessen the environmental stresses [14]. Glycine betaine improve tolerance in crops against environmental stresses including salt stress either applied exogenously or by transgenic approach $[15,16,17]$. Glycine betaine improved acceptance in plants in contradiction of salt strain through mechanism by protecting membrane veracity, reduce oxidation in membrane lipids and activation of enzymes [18]. Glycinebetaine is extremely rich in chloroplast 
and most vital part in resistance to thylakoid membrane and upholding photosynthetic efficacy [19]. Though, several techniques have been experienced on plants. These well-suited solutes hold water within cells and protect cellular sector from injury produced by dehydration, throughout water deficiency. GB recover crop growth and seedling development under water deficit conditions [20]. It is also used to increase the deficiency tolerance of several crops such as wheat, rice and cotton [21]. GB applied exogenously can improve the activities of anti-oxidative enzyme and plant has minor oxidative stress [22]. When the quantity of GB is low, carbon dioxide accommodation rise. Glycinebetaine also complicated in the osmotic adjustment, in cotton plants [23]. Likewise, GB rises strain tolerance by stopping photoinhibition and declining erosion of lipid membranes [24]. Glycine betaine also helpful in ion homeostasis and $\mathrm{Na}^{+} / \mathrm{K}^{+}$inequity when applied exogenously under salinity stress [25].

Hence, the current experiment was conducted to appraise the consequence of glycine betaine on two tomato genotypes under saline conditions by assessing their morphological and physiological attributes.

\section{Material and Methods}

This experiment was conducted to induce salt tolerance in two tomato genotypes (L00587 and L00602) by exogenously applied of glycine betaine at seedling stage. The research was carried out in Growth Chamber of Institute Horticulture Sciences of University of Agriculture Faisalabad, Pakistan. The seeds of two tomato genotypes were attained from Ayub Research Centre Faisalabad. There were four levels of GB $(0,5,10$ and $15 \mathrm{mM})$ applied. The sowing was carried out in medium size plastic pots and as the growth medium sand was used; before sowing the growth medium was washed with adequate distilled $\mathrm{H}_{2} \mathrm{O}$ to eradicate the salts already present in it. Hoagland's solution was applied as a source of nutrition. Through irrigation, salt stress was given after 20 days of germination of crop. Salinity level applied as $0,1.5$ and $3 \mathrm{dSm}^{-1}$ respectively for stress and control conditions. After 7 days of salt application glycine betaine was applied. There were four levels of GB (0, 5,10 and $15 \mathrm{mM})$. Completely randomized design with three repeats was used to conduct this experiment.

Following treatment were used:

$\mathrm{T}_{0}=$ Control (Non-saline + No spray)

$\mathrm{T}_{1}=1.5 \mathrm{ds} \mathrm{m}^{-1}+$ No spray of glycine betaine

$\mathrm{T}_{2}=1.5 \mathrm{ds} \mathrm{m}^{-1}+5 \mathrm{mM}$ of glycine betaine

$\mathrm{T}_{3}=1.5 \mathrm{ds} \mathrm{m}^{-1}+10 \mathrm{mM}$ of glycine betaine

$\mathrm{T}_{4}=1.5 \mathrm{ds} \mathrm{m}^{-1}+15 \mathrm{mM}$ of glycine betaine

$\mathrm{T}_{5}=3 \mathrm{ds} \mathrm{m}^{-1}+$ No spray of glycine betaine

$\mathrm{T}_{6}=3 \mathrm{ds} \mathrm{m}^{-1}+5 \mathrm{mM}$ of glycine betaine

$\mathrm{T}_{7}=3 \mathrm{ds} \mathrm{m}^{-1}+10 \mathrm{mM}$ of glycine betaine

$\mathrm{T}_{8}=3 \mathrm{ds} \mathrm{m}^{-1}+15 \mathrm{mM}$ of glycine betaine

Subsequently 40 days of growth the seedlings were uprooted; morphological attributes (root and shoot length, number of leaves, plant fresh weight, plant dry weight) and physiological attributes (chlorophyll content, relative water content, osmotic potential, electrolyte leakage, water potential) were recorded. Recorded data were statistically scrutinized using ANOVA. Data collection methods mentioned in table 1. 
Table 1. Morphological and Physiological attributes

\begin{tabular}{|c|c|c|}
\hline \multirow{5}{*}{ 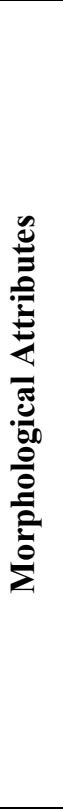 } & $\begin{array}{l}\text { No. of plant } \\
\text { leaves }\end{array}$ & $\begin{array}{l}\text { After thirty five days of growth the seedlings were uprooted and washed with distilled water to } \\
\text { remove the foreign particles of sand. Total number of leaves of seedling counted for each plant } \\
\text { for each replication. At the end the average was computed. }\end{array}$ \\
\hline & $\begin{array}{l}\text { Measurement } \\
\text { of root } \\
\text { lengths }(\mathrm{cm})\end{array}$ & $\begin{array}{l}\text { After forty days of growth the seedlings were uprooted and washed with distilled water to } \\
\text { remove the foreign particles of sand. Root length of two randomly selected seedlings from } \\
\text { each replicate were measured in centimeters }(\mathrm{cm}) \text { from the base of hypocotyls to tip of the root } \\
\text { with the help of meter rod. The average of each replication was calculated. }\end{array}$ \\
\hline & $\begin{array}{l}\text { Measurement } \\
\text { of shoot } \\
\text { lengths }(\mathrm{cm})\end{array}$ & $\begin{array}{l}\text { After forty days of growth, the seedlings were uprooted and washed with distilled water to } \\
\text { remove the foreign particles of sand. Shoot length of two randomly selected seedlings from } \\
\text { each replicate were measured in centimeters }(\mathrm{cm}) \text { from the base of hypocotyls to the tip of the } \\
\text { shoot with the help of meter rod. The average of each replication was calculated. }\end{array}$ \\
\hline & $\begin{array}{l}\text { Plant fr } \\
\text { weight }\end{array}$ & $\begin{array}{l}\text { After forty days of growth, two plants from each replicate were gently up rooted and washed } \\
\text { with distilled water to remove the sand particles. After washing these plants were wrapped with } \\
\text { filter paper to remove any drop of water present on their leaves and shoots. Then these were } \\
\text { placed on the digital balance for the calculation of fresh weights. And average fresh weight of } \\
\text { each replicate was recorded. }\end{array}$ \\
\hline & & $\begin{array}{l}\text { After measuring the fresh weights the plant material from each replicate was taken in paper } \\
\text { bags and then placed in dring oven (Memmert- } 110 \text {, Schawabach) dried at } 72^{\circ} \mathrm{C} \text { for a week of } \\
\text { drying the dried biomass was calculated on digital balance and average dry weight of each } \\
\text { replicate was taken. }\end{array}$ \\
\hline \multirow{5}{*}{ 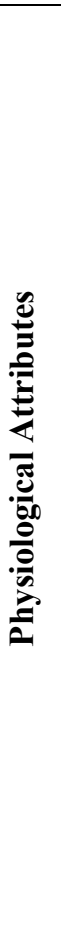 } & $\begin{array}{r}\text { Chloro } \\
\text { conte }\end{array}$ & $\begin{array}{l}\text { Chlorophyll a and b contents of the fresh material of plant were estimated from Aron method } \\
\text { (1949). In eighty percent acetone } 100 \mathrm{mg} \text { of the fresh material of plant was extracted. The } \\
\text { measurements were made on spectrophotometer (Hitachi-U2001, Tokyo, Japan) using } 645 \mathrm{~nm} \\
\text { and } 663 \mathrm{~nm} \text {. The contents of chlorophyll a and b were calculated by using following formulae. } \\
\text { Chl. a (mg g }-1 \text { f.wt.) }=(1.27 \text { (OD663) }-2.699(\text { D645) } \times 5 / 1000 \times 0.1 \\
\text { Chl.b (mg g-1 f.wt.) }=(22.9 \text { (OD645)-4.68(0D663) } \times 5 / 1000 \times 0.1\end{array}$ \\
\hline & $\begin{array}{l}\text { Water } \\
\text { potential of } \\
\text { leaf }(-\mathrm{MPa})\end{array}$ & $\begin{array}{l}\text { After forty days of plant growth third fully ex } \\
\text { replicate treatment }{ }^{-1)} \text { was cut with a razor } \\
\text { morning before the } 12.00 \text { am }(10.00 \text { am to } 1\end{array}$ \\
\hline & $\begin{array}{l}\text { Osmotic } \\
\text { potential of } \\
\text { leaf }(-\mathrm{MPa})\end{array}$ & $\begin{array}{l}\text { The same leaf that was used in pressure chamber for Osmotic potential was placed in a plastic } \\
\text { bag and kept at low temperature }\left(-20^{\circ} \mathrm{C}\right) \text { in a freezer for a week. The frozen leaf material was } \\
\text { then thawed at room temperature for half hour and cell sap was extracted with the help of a } \\
\text { disposable syringe. The } 10 \mu \text { l of extracted sap was placed on osmometer (Wescor Model-5500) } \\
\text { with the help of plastic syringe and Osmotic Potential measurement was taken. }\end{array}$ \\
\hline & $\begin{array}{l}\text { Relative } \\
\text { water } \\
\text { contents } \\
\text { (RWC) }\end{array}$ & $\begin{array}{l}\text { Fully prolonged leaves were sampled and weighed to take fresh leaf weight. To obtain fully } \\
\text { turgid weight the leaf sample were placed into water for three hours. Then the leaves were } \\
\text { removed from water and oven dried at } 70 \% \text { for } 24 \text { hours and noted the dry weight. } \\
\text { Following formula was used to calculate RWC; } \\
\text { RWC } \%=\text { fresh wt - dry wt / turgid wt - dry wt } \times 100\end{array}$ \\
\hline & $\begin{array}{l}\text { Electrolyte } \\
\text { leakage } \\
\text { (\%age) }\end{array}$ & $\begin{array}{l}\text { After forty days two plants from each replicate was taken and dipped in test tube. The distilled } \\
\text { water present in the test tube and then measure the density of the plants from test tube. And } \\
\text { then these test tube was autoclave at } 121^{0} \mathrm{C} \text { for } 15 \text { minutes in } 15 \text { psi. Then again measure the } \\
\text { density of test tubes with Electro leakage meter. }\end{array}$ \\
\hline
\end{tabular}

\section{Results}

\section{Morphological Attributes:}

Number of leaves: Analysis of variance (ANOVA) for the data of number of leaves shows that salinity stress significantly reduces the number of leaves for both tomato genotypes. And with reference to this attribute both genotypes differ significantly. When exogenously glycine betaine applied both genotypes showed improvement and enhance number of leaves under saline conditions. (Fig. 1).

Root Length: Plant root length reduced significantly under the salt treatments but three i.e. $5 \mathrm{mM}, 10 \mathrm{mM}$ and $15 \mathrm{mM}$ level of glycine betaine improved this attribute of both genotypes. $15 \mathrm{mM}$ was most effective than $5 \mathrm{mM}$ and $10 \mathrm{mM}$ glycine betaine application (Fig. 2).

Shoot Length: Plant root length reduced significantly under the salt treatments but three i.e. $5 \mathrm{mM}, 10 \mathrm{mM}$ and $15 \mathrm{mM}$ level of glycine betaine improved this attribute of both genotypes. $15 \mathrm{mM}$ was most effective than $5 \mathrm{mM}$ and $10 \mathrm{mM}$ glycine betaine application (Fig. 3). 
Plant Fresh Weight: Plant fresh weight of both tomato genotypes was expressively abridged by salinity conditions while the applications of glycine betaine induce the tolerance and improvement against salinity. 15mM application of GB more effective in L00587 as compare to L00602 (Fig. 4).

Plant Dry Weight: Plant fresh weight of both tomato genotypes was importantly abridged by salinity conditions while the applications of glycine betaine induce the tolerance and improvement against salinity. 15mM application of GB more effective in L00587 as compare to L00602 (Fig. 5).

\section{Physiological Attributes:}

Chlorophyll Content: In two tomato genotypes net considerable reduction of chlorophyll content observed under the salt treatment. And with reference to this attribute both genotypes differ significantly. Recovery showed as the result of exogenous application of glycine betaine (Fig. 6).

Water Potential: Statistical analysis for variance of the water potential attribute shows that salinity badly affected the water potential, but this attribute shows recovery as the result of the foliar application of glycine betaine. $5 \mathrm{mM}, 10 \mathrm{mM} 15 \mathrm{mM}$ glycine betaine exogenous application more effective under $1.5 \mathrm{ds} \mathrm{m}^{-1}$ salt concentration (Fig. 7).

Osmotic Potential: Analysis of variance for osmotic potential indicates that this attribute showed the significant reduction against the salinity stress. As concerned this attribute, both genotypes showed significant difference. Application of glycine betaine improve the osmatic potential against salinity stress (Fig. 8).

Relative Water Content: Statistical analysis for variance of the relative water content attribute shows that salinity badly affected the relative water content percentage, but this attribute shows recovery as the result of the foliar application of glycine betaine. $15 \mathrm{mM}$ glycine betaine more effective under $1.5 \mathrm{ds} \mathrm{m}^{-1}$ salt concentration (Fig. 9).

Electrolyte Leakage: Electrolyte leakage jumped up under the saline condition; much higher in $3 \mathrm{ds} \mathrm{m}^{-1}$ salinity level. This attribute reduced by the effect of glycine betaine under salinity stress. All levels of glycine betaine effective (Fig. 10).

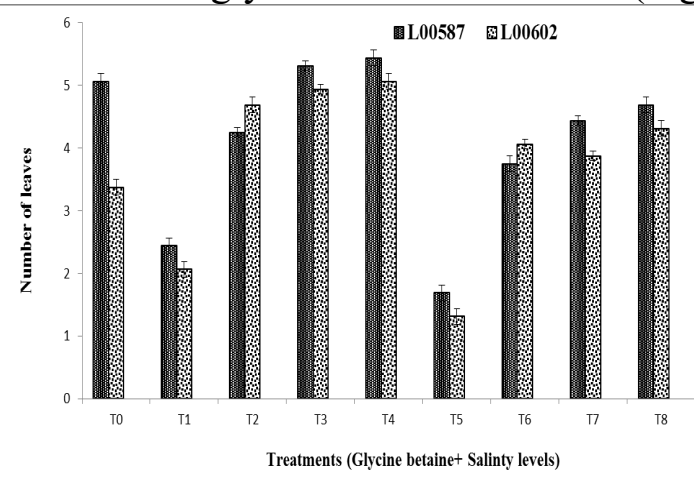

Fig. 1. Effect of glycine betaine on number of leaves of tomato genotypes under salinity

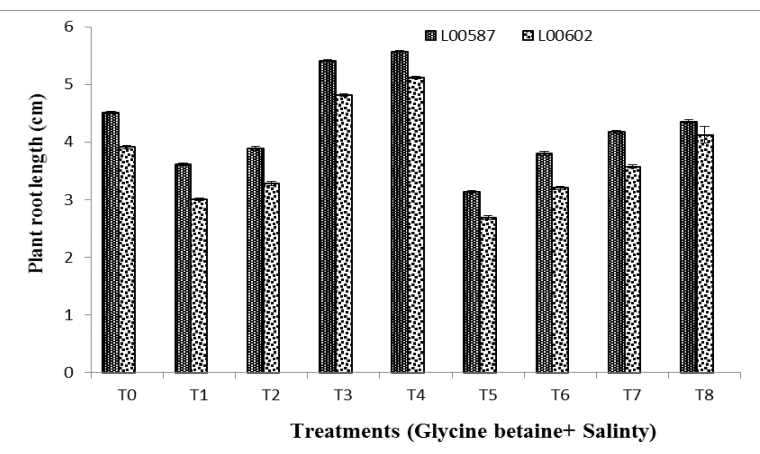

Fig. 2. Effect of glycine betaine on plant root length of tomato genotypes under salinity

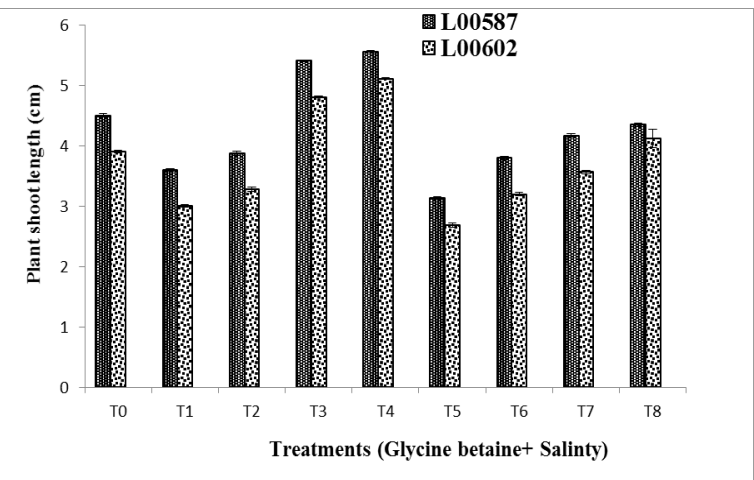

Fig. 3. Effect of glycine betaine on plant shoot length of tomato genotypes under salinity

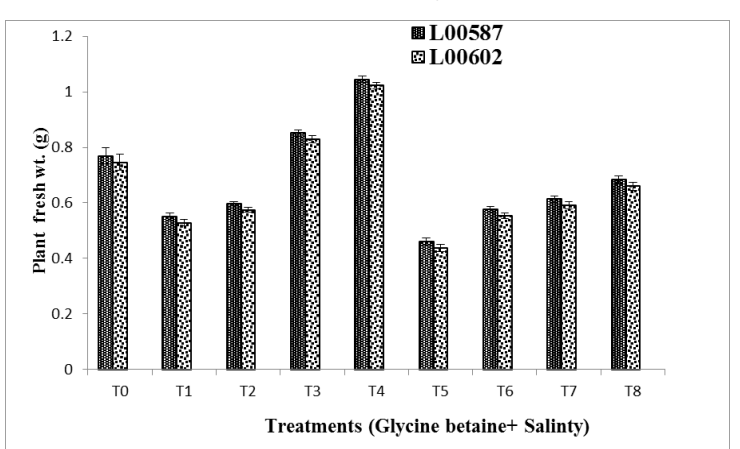

Fig. 4. Effect of glycine betaine on plant fresh weight of tomato genotypes under salinity 


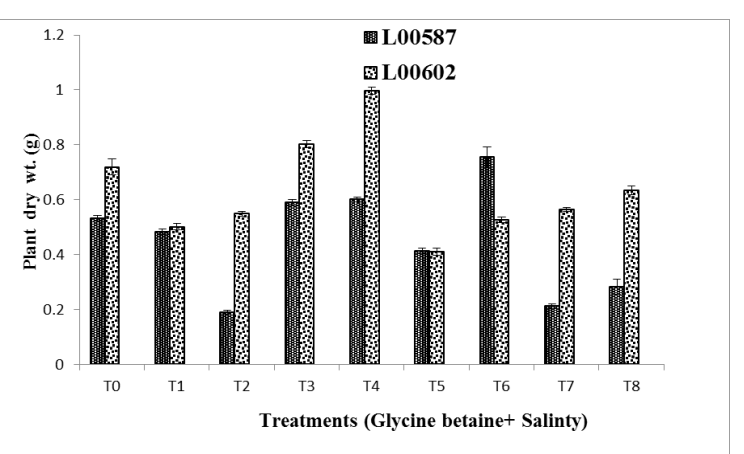

Fig. 5. Effect of glycine betaine on plant dry weight of tomato genotypes under salinity

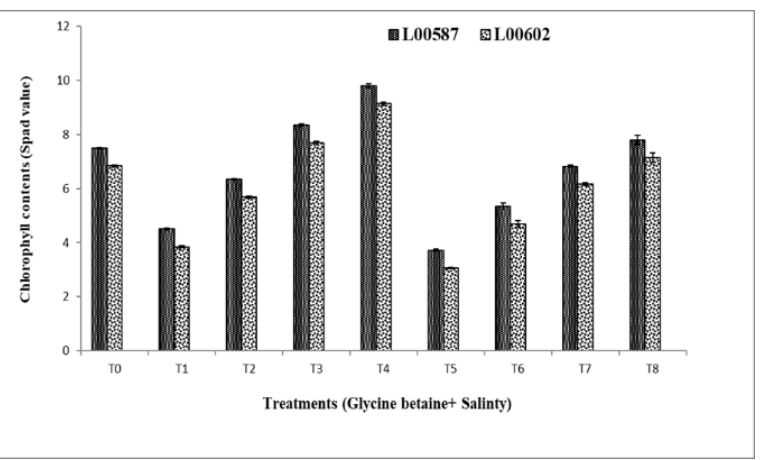

Fig. 6. Effect of glycine betaine on chlorophyll content of tomato genotypes under salinity

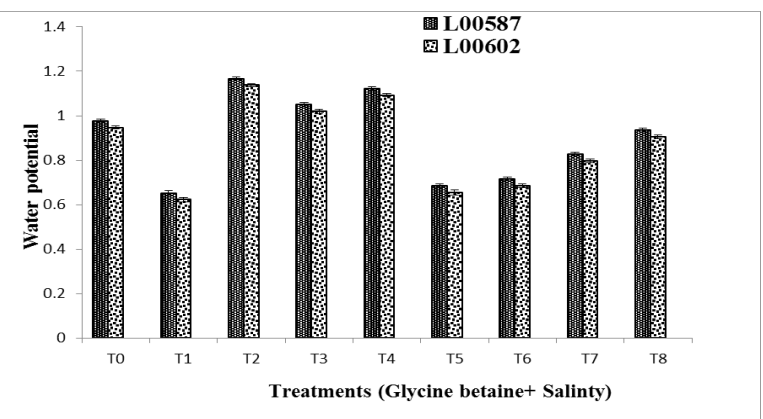

Fig. 7. Effect of glycine betaine on water potential of tomato genotypes under salinity

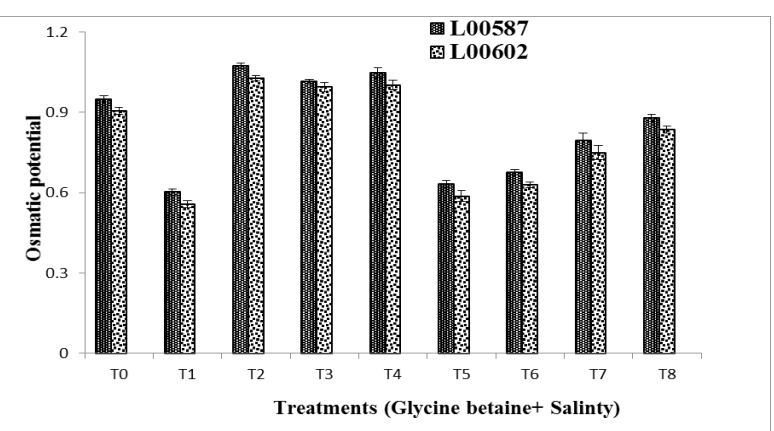

Fig. 8. Effect of glycine betaine on osmotic potential of tomato genotypes under salinity

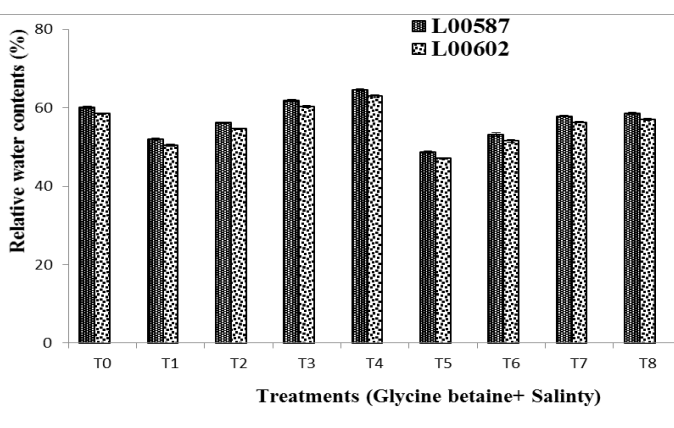

Fig. 9. Effect of glycine betaine on relative water content of tomato genotypes under salinity

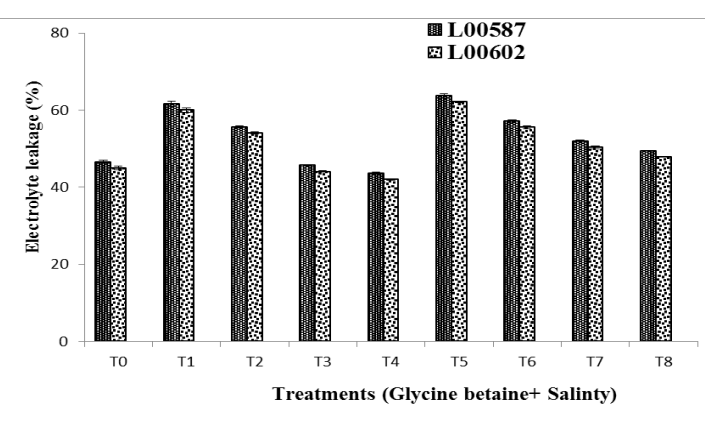

Fig. 10. Effect of glycine betaine on electrolyte leakage of tomato genotypes under salinity

Table 2. LSD mean comparison results of tomato genotypes for various traits

\begin{tabular}{|c|c|c|c|c|c|c|c|c|c|c|}
\hline Treatments & NOL & PRL & PSL & PFWT & PDWT & $\mathrm{CC}$ & EL & RWC & WP & OP \\
\hline $\mathbf{T}_{\mathbf{0}}$ & $5.95 \mathrm{~b}$ & $5.2348 \mathrm{~cd}$ & $6.1292 \mathrm{~b}$ & $0.8950 \mathrm{~d}$ & $0.8567 \mathrm{~b}$ & $9.107 \mathrm{~d}$ & $73.173 \mathrm{~d}$ & $77.057 \mathrm{~d}$ & $1.2267 \mathrm{e}$ & $1.2088 \mathrm{c}$ \\
\hline$T_{1}$ & $3.00 \mathrm{~d}$ & $4.4100 \mathrm{f}$ & 4.5967 ef & $0.7187 \mathrm{~g}$ & $0.5200 \mathrm{c}$ & $5.563 \mathrm{~h}$ & $59.873 \mathrm{~g}$ & $68.257 \mathrm{~h}$ & $0.8500 \mathrm{i}$ & $0.8133 \mathrm{~g}$ \\
\hline $\mathbf{T}_{2}$ & $5.48 \mathrm{bc}$ & $4.7800 \mathrm{e}$ & $5.2650 \mathrm{~cd}$ & 0.7817 ef & $0.6150 \mathrm{c}$ & $8.007 \mathrm{f}$ & $64.870 \mathrm{f}$ & $73.913 \mathrm{f}$ & $0.9333 \mathrm{~g}$ & $1.0300 \mathrm{e}$ \\
\hline $\mathbf{T}_{3}$ & $6.83 \mathrm{a}$ & $6.8167 \mathrm{~b}$ & $8.2778 \mathrm{a}$ & $1.1208 \mathrm{~b}$ & $0.9602 \mathrm{ab}$ & $10.677 \mathrm{~b}$ & $81.090 \mathrm{~b}$ & $81.433 \mathrm{~b}$ & $1.4767 \mathrm{~b}$ & $1.3667 \mathrm{ab}$ \\
\hline $\mathbf{T}_{4}$ & $7.00 \mathrm{a}$ & $7.1233 \mathrm{a}$ & $8.6233 \mathrm{a}$ & $1.3783 \mathrm{a}$ & $1.0683 \mathrm{a}$ & $12.613 \mathrm{a}$ & $83.910 \mathrm{a}$ & $85.010 \mathrm{a}$ & $1.5367 \mathrm{a}$ & $1.4000 \mathrm{a}$ \\
\hline $\mathbf{T}_{5}$ & $2.00 \mathrm{e}$ & $3.8867 \mathrm{~g}$ & $4.1417 \mathrm{f}$ & $0.5983 \mathrm{~h}$ & $0.4950 \mathrm{c}$ & $4.513 \mathrm{i}$ & $57.050 \mathrm{~g}$ & $63.910 \mathrm{i}$ & $0.8233 \mathrm{j}$ & $0.7733 \mathrm{~h}$ \\
\hline$T_{6}$ & $5.20 \mathrm{c}$ & $4.6700 \mathrm{e}$ & $4.8600 \mathrm{de}$ & $0.7542 \mathrm{f}$ & $0.5517 \mathrm{c}$ & $6.687 \mathrm{~g}$ & $60.050 \mathrm{~g}$ & $71.833 \mathrm{~g}$ & $0.8933 \mathrm{~h}$ & $0.8700 \mathrm{f}$ \\
\hline $\mathbf{T}_{7}$ & $5.54 \mathrm{bc}$ & $5.1667 \mathrm{~d}$ & $5.5917 \mathrm{c}$ & $0.8021 \mathrm{e}$ & $0.6583 \mathrm{c}$ & $8.660 \mathrm{e}$ & $68.167 \mathrm{e}$ & $76.093 \mathrm{e}$ & $1.0833 \mathrm{f}$ & $1.1433 \mathrm{~d}$ \\
\hline $\mathbf{T}_{8}$ & $6.00 \mathrm{~b}$ & $5.3783 \mathrm{c}$ & $8.2667 \mathrm{~b}$ & $0.9936 \mathrm{c}$ & $0.9300 \mathrm{ab}$ & $9.947 \mathrm{c}$ & $75.097 \mathrm{c}$ & $78.007 \mathrm{c}$ & $1.3800 \mathrm{c}$ & $1.3400 \mathrm{~b}$ \\
\hline
\end{tabular}

$\mathrm{NOL}=$ No. of leaves, $\mathrm{PRL}=$ Plant root length, PSL = Plant shoot length, PFWT= Plant fresh weight, PDWT= Plant dry weight, $\mathrm{CC}=$ Chlorophyll contents, $\mathrm{EL}=$ Electrolyte leakage, $\mathrm{RWC}=$ Relative water content, $\mathrm{WP}=\mathrm{W}$ ater potential, $\mathrm{OP}=\mathrm{Osmotic}$ potential 


\section{Discussions}

Table 2. presented the mean comparison distribution among various traits under different treatments. Salt adversely affect the biomass of the two tomato genotypes and these results related to the previous studies that saline conditions during plant growth limited to the water absorption, reduce the biochemical reactions distributions and also caused decrease in leaf area [26]. So, these changes refereed to negative response of biomass of tomato plant. The adversative consequence on plant length, plant fresh and dry weight instigated by salinity in our experiment were observed. Results revealed that when glycine betaine applied exogenously in salinity conditions increase in plant fresh and dry weight occurred and the similar finding were found in many earlier experiments [10,27]. By the exogenous application of glycine betaine dry weight augmented because the photosynthetic action increased by glycine betaine. Zhang et al., [28] avowed similar findings. It has been observed by preceding studies that exogenous treatment of glycinebetaine enhanced the growth of plant under salinity and non-salinity conditions because of enhanced doings of antioxidant that lessen the stress hurt.

Number of leaves reduced is response to effect of salinity. Parvin et al., [29] and Jafari et al., [30] described similar outcomes. Glycine betaine help to reduce salinity and enhancing leaf numbers. Root and shoot length abridged in response to salt stress, alike these findings Kausar et al. [10] derived results and showed progress in response to exogenous application of glycine betaine.

This study indicated that relative water content diminished by the salinity conditions. Hu et al. [18] showed similar results and also Alasvandyari and Mahdavi [31] indicated these findings. The reduction in chlorophyll content recovered in response to glycine betaine effect [18]. Salinity deteriorated water potential and osmotic potential because $\mathrm{Na}^{+} / \mathrm{K}^{+}$ratio disturbed by salt. Glycine betaine rehabilitate water potential and osmotic potential for proper cell functions [32].

The present study indicated that electrolyte leakage increased due to salt stress, because of more oxidative damage. Glycine betaine's exogenous application reduce this oxidative damage and help to reduce electrolyte leakage. Similar findings were reported in many earlier experiments [33]. Our results exhibited that exogenous application of glycinebetaine increased the salinity tolerance in tomato. In non-saline condition than in salinity conditions, external importance of glycinebetaine in fresh and dry weight of shoot and root recommended that glycinebetaine is strongly maintained in the plant growth parameter.

\section{Conclusion}

It can be determined based on results that salt stress putting adverse impact on the growth of tomato plant; its morphological and physiological attributes. Glycine betaine exogenously application significantly mitigating the deleterious properties of salinity condition. $15 \mathrm{mM}$ glycine betaine proved more effective as compare to $5 \mathrm{mM}$ and $10 \mathrm{mM}$. As the end point glycine betaine induced resistance against salt stress in both tomato genotypes.

\section{References}

[1] FOA. 2016. Food and Agriculture Organization of the United Nations, Rome, Italy.

[2] Anonymous, Working paper. Meeting of the federal committee on agriculture (FCA). Ministry of National Food Security and Research (NFS\&R). 2015.

[3] M. Hassan et al., Effects of salt and water stress on plant growth and on accumulation of osmolytes and antioxidant compounds in cherry tomato, Not. Bot. Horti. Agrobo. 43 (2015) 111.

[4] A. Parvaiz, S. Satyawati, Salt stress and phyto-biochemical responses of plants: a review. Plant Soil Environ. 53 (2007) 89-99.

[5] M. Ashraf, P. J. Harris. Potential biochemical indicators of salinity tolerance in plants, Plant Sci. 166 (2004) 3-16. 
[6] K. Yamane et al., Pretreatment with antioxidants decreases the effects of salt stress on chloroplast ultrastructure in rice leaf segments (Oryza sativa L.), Plant Prod. Sci. 7 (2004) 292300 .

[7] S. Negrão, S. M. Schmöckel, M. Tester, Evaluating physiological responses of plants to salinity stress, Annals Bot. 119 (2017) 1-11.

[8] V. Chinnusamy, A. Jagendorf, J. K. Zhu, Understanding and improving salt tolerance in plants, Crop Sci. 45 (2005) 437-448.

[9] M. Pal et al., Photosynthetic characteristics and activity of enzymes in salinity tolerant and sensitive rice cultivars, Indian J. Plant Physiol. 9 (2004) 407-412.

[10] N. Kausar et al., Effect of Exogenous Applications of Glycine Betaine on Growth and Gaseous Exchange Attributes of Two Maize (Zea mays L.) Cultivars under Saline Conditions, Applied Sci. J. 29 (2014) 1559-1565.

[11] M. Hameed et al., Structural and functional adaptations in plants for salinity tolerance. In Plant Adaptation and Phytoremediation, Springer, Dordrecht. (2010). pp. 151-170.

[12] Y. Tada, S. Komatsubara, T. Kurusu, Growth and physiological adaptation of whole plants and cultured cells from a halophyte turf grass under salt stress. AoB Plants, 6 (2014) https://doi.org/10.1093/aobpla/plu041

[13] M. A. Hoque et al., Exogenous proline mitigates the detrimental effects of salt stress more than the betaine by increasing antioxidant enzyme activities, J. Plant Physiol. 164 (2007) 553-61.

[14] T. H. Chen, N. Murata, Glycinebetaine protects plants against abiotic stress: mechanisms and biotechnological applications, Plant Cell Environ. 34 (2011) 1-20.

[15] M. Ashraf, M. R. Foolad, Improving plant abiotic-stress resistance by exogenous application of osmoprotectants glycinebetaine and proline, Environ. Exp. Bot. 59 (2007) 206-216.

[16] M. Shahbaz et al., Is foliar-applied glycinebetaine effective in mitigating the adverse effects of drought stress on wheat (Triticum aestivum L.), J. Appl. Bot. Food. Qual., 84 (2011) 192-199.

[17] A. Sorwong, S. Sakhonwasee, Foliar Application of Glycine Betaine Mitigates the Effect of Heat Stress in Three Marigold (Tagetes erecta) Cultivars, The Horti. J. 84 (2015) 161-171.

[18] L. Hu et al., Exogenous glycine betaine ameliorates the adverse effect of salt stress on perennial ryegrass, J. Amer. Soc. Hort. Sci. 137 (2012) 38-46.

[19] P. Lamosa et al., Protein stabilization by compatible solutes. The FEBS J., 270 (2003) 46064614.

[20] K. Nahar, R. Gretzmacher, Response of shoot and root development of seven tomato cultivars in hydrophonic system under water stress. Acadmical J. Plant Sci., 4 (2011) 57-63.

[21] S. Rahman, Effects of exogenous glycinebetaine on growth and ultrastructure of salt-stressed rice seedlings (Oryza sativa L.). Plant Production Sci., 5 (2002) 33-44.

[22] M. A. Rezaei et al., Morpho-physiological improving effects of exogenous glycine betaine on tomato (Lycopersicum esculentum Mill.) cv. PS under drought stress conditions. Plant Omics, 5 (2006) 79-87.

[23] D. A. Meloni, C. A. Martínez, Glycinebetaine improves salt tolerance in vinal (Prosopisrus cifolia Griesbach) seedlings. Brazilian J. Plant Physiol., 21 (2009) 233-241.

[24] T. Demiral, I. Türkan, Does exogenous glycinebetaine affect antioxidative system of rice seedlings under $\mathrm{NaCl}$ treatment? J. Plant Physiol., 161 (2004) 1089-1100.

[25] M. A. Hamdia, M. A. K. Shaddad. Salt tolerance of crop plants, J. Stress Physiol. Biochem. 6 (2010) 64-90. 
[26] A. K. Parida, A. B. Das, Salt tolerance and salinity effects on plants: A Rev. Ecotoxicol. Environ. Safety, 60 (2005) 324-349.

[27] A. M. R. Abdel-Mawgoud, Soil and foliar applications of glycinebetaine ameliorate salinity effects on squash plants grown under bahraini conditions, Middle East J. 6 (2017) 315-322.

[28] H. Zhang et al., Increased glycine betaine synthesis and salinity tolerance in AhCMO transgenic cotton lines. Mol. Breeding, 23 (2009) 289-298.

[29] K. Parvin et al., Response of tomato plant under salt stress: Role of exogenous calcium, J. Plant Sci., 10 (2015) 222-233.

[30] H.S. Jafari, M. Kafi, A.R. Astaraei, Interactive effects of $\mathrm{NaCl}$ induced salinity, calcium and potassium on physiomorphological traits of sorghum (Sorghum bicolor L.), Pak. J. Bot. 41 (2009) 3053-3063.

[31] F. Alasvandyari, B. Mahdavi, Effect of glycinebetaine on growth and antioxidant enzymes of safflower under salinity stress condition, Agric. For. 63 (2017) 85-95.

[32] M. A. Raza et al., Exogenous application of glycinebetaine and potassium for improving water relations and grain yield of wheat under drought, J. Soil Sci. Plant Nutri. 14 (2014) 348-364.

[33] Z. Kaya et al., Mitigation effects of glycinebetaine on oxidative stress and some key growth parameters of maize exposed to salt stress, Turk. J. Agric. For. 37 (2013) 188-194. 